Karadeniz Uluslararası Bilimsel Dergi

Volume: 40, Winter-2018, p. (271-287)

ISSN: 1308-6200 DOI Number: 10.17498/kdeniz.483100

Research Article

Received: November 15, 2018 Accepted: December 05, 2018

This article was checked by iThenticate.

\title{
CÖNKLER VE “CELALI” MAHLASIYLA YAZILMIŞ BİR CÖNK
}

\section{POETRY COMPILATIONS AND A COMPILATION WITH "CELALI" NICKNAME}

\section{СБОРНИК ПОЕТИЧЕСКИХ НАРОДНЫХ ПРОИВЕДЕНИИ (ДЖЁНКЛЕР) С ПСЕВДОНИМОМ "ДЖЕЛАЛИ"}

Mirza POLAT*

ÖZ

Halk edebiyatının önemli kaynaklarından biri olarak kabul edilen cönkler, sistemli bir şekilde yazılmamış ancak halkın içinden çıkan edebi şahsiyetlerin eserlerini günümüze ulaştırmada önemli bir kaynak görevi görmüştür. Cönkün ne olduğu ile ilgili pek çok tanım yapılmıştır. Bu tanımlamaların bazılarına aşağıdaki yazımızda yer verdik.

Okumaya çalıştığımız cönk Celali mahlasıyla yazılmıştır. Cönkün başında Raif Yelkenci Cönkü No: 8 yazmaktadır. Bir sonraki sayfada ise Latin rakamları ile 1622 tarihi yazılmaktadır. Cönkte bulunan şiirler iki mısra şeklinde yazılarak toplam 23 sayfadır. Şiirlerden ilki bir satirik şiir özelliği göstermektedir. Cönkte birden çok şiir türü bulunmakla birlikte bir de gazel vardır. Cönkün okunması esnasında karşılaşılan sorunlar ve çözümlerine dair fikirleri aşağıda zikrettik.

Cönkteki şiirlerde şair genel bir güzellemeden sonra İstanbul ile ilgili bir güzelleme yazmıştır. Şiirde İstanbul semtlerinin isimlerini belirterek yazmış ve genel çerçevede Topkapı, Galata, Beyoğlu gibi İstanbul'un gözde yerlerini şiire konu etmiştir. Tahminimizce cönkte şiirleri bulunan şair saraya yakın biridir. Zira şiirlerinde devlet erkanına karşı bir övgü söz konusudur. Şair şiirlerinde ordudan ve ordu mensuplarından da bahsetmektedir.

Okuduğumuz cönkün yazarının İstanbul'da yaşayan bir asker olma ihtimali yüksektir. Zira yazmış olduğu şiirler içinde Yeniçeri ocağının geçmesi, Bektaşi ile ilgili kısımların yoğun olması ve Bektaşi’ye karşı bir övgünün olması bu tahminde bulunmamızı sağlamıştır. Cönkü yazan kişi imla ile ilgili herhangi bir çıkarımda bulunmadan serbest bir şekilde kalemini kullanmıştır. Aynı kelimeleri farklı şekilde yazmışıı. Bu da metni okumamızı biraz zorlaştırmıștır. Ancak buna rağmen cönkte okunamayan bir yer yoktur. Sadece cönkteki silinme ve kopmalardan dolayı eksiklik vardır.

Anahtar Kelimeler: Cönk, Celali, İstanbul, Bektaşi, Raif Yelkenci.

* ORCID: 0000000304001388 Araş. Gör. Ardahan Üniversitesi, İBEF, mirzapolat@ardahan.edu.tr 
ABSTRACT

Poetry compilations accepted as an important source of folk litareture have played a significant role in delivering the works of literary figures, which were not analysed systemically but produced by the folk. Many definitions have been made as to what a poetry collection is. Some of these definitions are presented in our study.

The poetry compilation we tried to read is produced with "Celali" nickname. At the beginning of the compilation "Raif Yelkenci Poetry Compilation No:8" is written. On the next page a date of 1622 , in Latin numericals, is presented. There are 23 poems in the compilation composed in two lines. The first poem is in the style of a satire. Though there are many different poetic forms, a lyrical poem is also added. We presented the difficulties and solutions for the problems encountered during the reading of the compilation.

Following a general praise in poems, the poet begins to praise the beauty of İstanbul. He mentions various districts of İstanbul, and then a general picture of central places such as Topkap1, Galata and Beyoğlu is presented. It is our prediction that the poet must be someone close to the state, for he praises soem members of the state in his poems. He also mentions the army and some of its members.

It highly likely that the poet of the compilation is a military officer residing in İstanbul. In the poems he composed, he mentions the Janissery troops, and the Bektaşi people in particular, in an appraising style, which strengthens our supposition. He does not pay attention to the grammar rules or punctuation, instead, he composes his poems in free style, which made it difficult to read the poems. Yet, despite these difficulties, all the poems were successfully read. There aresome missing parts due to diminishing of writing or tearing of the pages.

Keywords: Poetry Compilation, Celali, İstanbul, Bektaşi, Raif Yelkenci

\section{АННОТАЦИЯ}

Джёнки, как один из важных элементов народной литературы, являются источником для представления о произведениях тех литературных деятелей, которые не подвергались системе правописания. Однако, они являлись плодом народного творчества. Джонк имеет разные определения. В нижеследующей статье рассматриваются некоторые из них.

Прочитанный нами сборник поетических народных произведении имеет псевдоним “Джелали”. В антологии первым произведением является сборник стихотворении Раифа Елкенджи. На первом странице этого указан o:8, а на следующей странице имеется дата 1622 г. В нём стихи написаны в двух мысрах и состоит из 23-х страниц. Первое стихотворение состоит из одной строки. В Джёнке, наряду с более чем одного типа поэзии имеется и одно лирическое стихотворение. Наши мнения по поводу сложностей при анализе Джёнка излагаются ниже.

В своей антологии, после общего введения, поэт хвалит стамбул и упоминает его такие замечательные кварталы, как Топкапы, Галата и Бейоглу. Считаем, что автор стихотворении этой антологии является человеком дворца. Так как, в стихотворениях хвалятся государственные деятели. Поэт, в своих стихотворениях упоминает армию и военных.

Есть большая вероятность, что автор антологии жыл в Стамбуле и являлся военным лицом. Так как, упоминание в его стихотворениях яничарского корпуса, отрывки по поводу бекташиев и хвола, подтвеждают наши предположения. Автор 
пишет совершенно свободно, не соблюдая какие либо правила правописания. Одни и те же слова написаны в разном стиле. Это осложняет работу над текстом. В текстах имеются недостатки в виде вычеркнутых и оторванных мест.

Ключевые слова: Джонк, Джелали, Истанбул, Бекташи, Раиф Елкенджи.

Halk edebiyatının en önemli kaynaklarından biri olan cönkler, sistemli bir şekilde yazılmamış olsalar da geçmişe ait halk edebiyatı ürünlerini günümüze kadar getirmede değerli bir araçtır. Cönkler hakkında pek çok araştırmacımız farklı tanımlamalar yapmışlardır. "Cava ve Malaya dillerindeki djong (conk) kelimesinden gelen cönk İspanyol ve Portekizce'ye junco, İtalyanca'ya giunco, Fransızca'ya jonque ve İngilizce’ye junk olarak geçmiş; Çin denizlerinde kullanılan dibi düz ve dört köşeli, puruvası, çıkıntılı baş bodoslaması ve kıç pupası, dümeni muallakta olan yelkenli gemiler için de genel bir ad olmuştur." Ayrıca cönk kelimesinin Türkçe olduğunu söyleyen Aka Seyyid Muhammed Ali, "türlü konuların, özellikle çeşitli şairlerden seçilmiş şiirlerin yazılı olduğu kitap veya defter" şeklinde tarif eder ve kelimenin Türkçe'de "büyük gemi, fakirlerin kullandığı satrançlı çul ve kilim, büyük nesne" anlamlarında kullanıldığını söyler( Gökyay, 1993:74)

Cönk üzerine pek çok araştırmacı bilim insanımız farklı tanımlar yapmışlardır aşağıda bu tanımlamalara yer verilmiştir.

" Başta halk şairlerinin şiiri olmak üzere çeşitli folklorik bilgilerin kaydedildiği ve uzunlamasına açılan( tulanî), sırtı dar, ensiz deri kaplı defter.” (Kaya, 2010:192)

Cönkler,“ âşık edebiyatı alanında önemli yazılı kaynaktır. Çoğunlukla âşık edebiyatı ürünlerini içeren; uzunlamasına açılan, ensiz, uzun defterlerdir. Günümüzde âşık edebiyatı, dini-tasavvufi edebiyat ve halkbilimi örneklerinin bulunduğu yazılı kaynakların başında gelen cönkler, yöntem yönünden modern olmasa bile ilk derlemelerin bulunduğu yerler olarak önemlidirler." ( Artun, 2014:114)

Cönklerin içeriği hususunda Orhan Şaik Gökyay şunları dile getirmiştir. "Genellikle âşıların, seyrek olarak da divan şairlerinin bir kısım şiirlerini ihtiva eden cönklerde çeşitli dualar, sihirle ilgili notlar, ilâç tarifleri, sahibini ilgilendiren doğum ve ölüm tarihleri, alacak verecek hesapları, anonim türkü, mâni ve ilâhiler, halk hikâyeleri ve daha birçok konu ile ilgili bilgiler bulunmaktadır. Halk, gezgin şairlerin uğradıklarl yerlerde söyledikleri türkü, koşma, destan ve fikralarl, hikâyeleri çok defa aklında tutabildiği kadarıyla eksik ya da yanlış olarak kâğıda geçirmiş; mâni ve bilmeceleri, kendi hayatıyla ilgili ve kendince gerekli birtakım hastalıkların tanımını, bunların tedavi yollarını, reçeteleri, tılsımları, özel hayatına ait notları bu defterlere yazmıs, böylece sayısı ve birbirinden çok farklı muhtevaya sahip cönkler meydana gelmiştir.” (Gökyay, 1993,74)

"Cönkler sözlü bellekteki otobiyografik ve kültürel malzemenin unutulmaması için yazıya geçirilmesi anlamında not defterleridir." (Duymaz, 2016:18)

"Az çok okuma yazma bilen âşılar ve sözlü geleneğe karşı ilgi duyan kişilerce yazıldiğı tahmin edilen ve "sı̆̆ır dili" ile "sefine" adlarıla da bilinen cönkler, içlerinde türkü mani, destan, koşma, atasözü, fikra, hikaye, bilmece, nefes, ilahi, menkabe gibi halk edebiyatı, âşık edebiyatı ve tekke-tasavvuf edebiyatı örneklerinin yanı sıra dua, hutbe, büyü, halk hekimliği, halk veterinerliği, tarihi olaylar ile ilgili bilgiler, cönkleri yazanların kişisel bilgileri, (doğum ve ölüm tarihleri, borçlar, vs.) de barındırmaktadırlar." (Aça, 2008:111)

Cönklerde sadece halk edebiyatı ürünleri aktarılmakla kalmamış aynı zamanda divan edebiyatı sınırları içindeki bazı şairlerin şiirleri de cönkler vasıtasıyla günümüze kadar gelmiştir. 
"Cönklerin çoğunda sayfa numarası yoktur. Kütüphanelerde muhafaza edilen bazı cönkler sonradan sayfa numarası verilmiştir. Cönkler genellikle "sığır (dana) dili" veya defter şeklinde olup standart bir ölçüye sahip değildir. Cönklerde divanlarda olduğu gibi sıralama söz konusu değildir. Diğer bir ifadeyle şiirler belirli bir siraya göre siralanmaz, tamamen keyfi bir durum söz konusudur.” ( Güzel- Torun, 2008:75)

Okumaya çalıştığımız aşağıdaki cönk farklı şiirlerden oluşmaktadır. Cönkte koşma başlığıyla bir şiir bulunmaktadır. Okuma sırasında karşımıza çıkan sorunları ve çözümleri şu şekilde sıralamamız mümkündür.

Metin içinde bazı kelimelerin bir kısmı deforme olduğundan okunamamakta idi. Bu kelimelerin ne olduğunu şiirin genel anlamda nelerden bahsettiğine bakarak çıkarmaya çalıştık.

Cönk içinde bazı dörtlüklerin iki mısrası silinmiş olduğundan buraları uzun nokta ile gösterdik.

Bazı kelimeler okunma esnasında farklı okumalara sebep olacak şekilde yazılmıştı. Yine bu kelimeleri nasıl yazıldığını da göz önüne alarak bağlamdan çıkarmaya çalıştık.

Bazı şiirlerde mısra başlarındaki kelimler silindiği için okuyamadık ve buralara uygun kelimeleri yerleştirmeyi de doğru bulmadığımız için bu silinen yerleri uzun nokta ile gösterdik.

Okumaya çalıştığımız cönk içinde eksik beyitleri olan bir gazel bulunmaktadır. Tahminimiz cönk bir kişiye ait olmayıp farklı şairlere ait olan şiirlerin başka biri tarafından yazıya geçirilmesi ile oluşmuştur.

Cönkün başında Raif Yelkenci Cönkü No: 8 yazmaktadır. Bir sonraki sayfada ise Latin rakamları ile 1622 tarihi yazılmaktadır. Cönkte bulunan şiirler iki mısra şeklinde yazılarak toplam 23 sayfadır. Şiirlerden ilki bir satirik şiir özelliği göstermektedir. Toplumumuzda kendi durumunu göz önünde bulundurmadan çok uçuk şeyler isteyen/dileyen kişiler için kullanılan "ayranı yok içmeye gümüş köprü ister geçmeye" deyimi tam olarak bu şiirde işlenmiştir. Ancak bu şiirde dikkatimizi çeken bir diğer husus da "Hemince gelmiş bak şu Türk'ün kabası/ Marsıvandan galmış böyük babası/ Yüz yerden yamalı yırtık abası/ Zerdava kürk hare kaftan beğenmez" mısralarında Türk’e karşı bir aşağılama durumunun dile getirilmesidir.

Cönkün ikinci şiirinde şair genel bir güzellemeden sonra İstanbul ile ilgili bir güzelleme yazmıştır. Şiirde İstanbul semtlerinin isimlerini belirterek yazmış ve genel çerçevede Topkapı, Galata, Beyoğlu gibi İstanbul'un gözde yerlerini şiire konu etmiştir.

Tahminimizce cönkte şiirleri bulunan şair saraya yakın biridir. Zira şiirlerinde devlet erkanına karşı bir övgü söz konusudur. Şair şiirlerinde ordudan ve ordu mensuplarından da bahsetmektedir.

Cönkün içindeki diğer bir şiirde şair tahtakurusunun onu rahatsız etmesinden muzdarip olacak ki tahtakurusunun onu nasıl rahatsız ettiği ile ilgili bilgileri şiirsel bir dille aktarmıştır. Tahtakurusu ile ilgili yazmış olduğu şiirde "Celali” mahlasını kullanan şair şiirin diğer dörtlüklerinde Bektaşi, Karacahmet gibi kişilerin himmet sahibi olmalarından da söz eder. Tahtakurusu ile ilgili şiiri bittikten sonra fikraya benzer bir sevgili tarifi anlatılmaktadır. Bu tarif tıpkı günümüz âşıklarından âşık Gül Ahmet tarafından yazılıp söylenen "Anamın Acer Gelini” adlı şiirin anlatımıyla benzerlik göstermektedir. Zira önce muhatap olunacak kız övülmekte ancak duvak açıldıktan sonra gerçek ortaya çıkmakta ve bu defa da kız en kötü şekilde eleştirilmektedir. Aslında bu şiir bir tarif etme anlamı taşımaktadır. 
Şair bir diğer şiirini Arap alfabesindeki harf sırasına göre yazmıştır. Yani her mısraın başını sırası gelen harf ile başlatmıştır. Ancak "tı-zı" harflerinin olduğu bölüm tamamen silindiği için okunamamıştır.

Cönkteki son şiir padişaha yapılan bir methiyedir. Ancak daha şiir bitmeden dört beyitlik bir gazel yazılmış ve gazelden sonra methiyeye devam edilmiştir.

Okuduğumuz cönkün yazarının İstanbul'da yaşayan bir asker olma ihtimali yüksektir. Zira yazmış olduğu şiirler içinde Yeniçeri ocağının geçmesi, Bektaşi ile ilgili kısımların yoğun olması ve Bektaşi’ye karşı bir övgünün olması bu tahminde bulunmamızı sağlamıştır. Cönkü yazan kişi imla ile ilgili herhangi bir çıkarımda bulunmadan serbest bir şekilde kalemini kullanmıştır. Aynı kelimeleri farklı şekilde yazmıştır. $\mathrm{Bu}$ da metni okumamızı biraz zorlaştırmıştır. Ancak buna rağmen cönkte okunamayan bir yer yoktur. Sadece cönkteki silinme ve kopmalardan dolayı eksiklik vardır.

\section{Raif Yelkenci Cönkü No: 8}

Evinde çapudı olmayan kişi

Bammug şilte döşek yorgan beğenmez

Salyan korkusundan sığır çobanı

Der saadete bir başmagçılar tabanı

Onu bir eşşeklen gelen yabani

Şimdi gör binmeye küheylan beğenmez

Ormandan ormana kaçıp yılanlar

Osman benden sille tokat yiyenler

Sobası soyrasta da dağdan gelenler

Bar cevahir hançeri bigane beğenmez.

Tabanları yarık gör ugubatı

Kir pastan görünmez çehre sıfatı

Çaynamadan yudar koklı bayatı

Şimdi sükker taam elan beğenmez.

Hemince gelmiş bak şu Türk'ün kabası

Marsıvandan galmış böyük babası

Yüz yerden yamalı yırtık abası

Zerdava kürk hare kaftan beğenmez

Meskeni yok gülman gülman sürünür

Kaba hasır barçasına bürünür

Yırtık dondan her arayı görünür

Çuha şalvar güz zimistan beğenmez.

Candan bezüp yerden yere gezenler

Çarı̆̆ını bu şehirde çözenler

Uğraman arasında mürekkep düzenler

Onaltı yaşında ceyran beğenmez 
Bir tarihi yazmıştır bunları yazan Bir alay müptezel dünyayı bozan Anadan babadan görmeyen hizan Yalıdın tavan köşki eyvan beğenmez

Yer yer gezip kulanını sürenler Gedayiden mertebeye inenler

Ekmekçinin daim hillede gözi Ya abıdır ya kürek mihnette sözi Ölür geder birdir yiğitnin sözi İkrar ile iman ne gözel uymuş

Pehlevan kisbet küleşmeye kanat Ma zalimlere kıyam asiye kemend Ata gümüş rahat tabgursuna bend Eşeklere palan ne gözel olmuş

Frenk aleme mahir katı hünerkar Sirke sarımsağa yapılır bulgar Bela ,,,,,,,,,,,,,,,, pek hain çifitleri var Başı kel şırlıgan ne gözel uymuş

Galata Beyoğlu arası uyumak Nev civana sükker pal ilen kaymak Borozana nefes tavula çomak Lavtaya keman ne gözel uymuş

Develere yayla çobana kaval Hanendeye usul-1 araba mabal Cenab-1 Kibriya vermeye zeval Her yazımdan biten ne gözel omuş

Boyacılar boyar her elvanı renk Gümüş altunı gösterir mehenk Devrişe çarık taç teslim bilenk Tekkelerde devran ne gözel olmuş

Paşalıya midras kartobu sarık Zerrin hançer belde elmas donanık Kadı hanı cengi kul başı çalık Galataya tavşan ne gözel olmuş

Birbirinin er alır neden iş Altun yalduz enam tabanca gümüş 
Yosma keseyim kartal kanadı biniş

Belde tabağı beygan ne gözel olmuş

Yeniçeri kadim zülema kisbet

Biri Hacı Bektaş sahibi keramet

Sayırdım ustası kahraman surat

Anlara yol erkan ne gözel olmuş

Bostancılar bir hoş başında bir oda

Kalyoncuda şehir yer semti Galata çabukluğa vardı rağbet her an ne gözel uymuş

Tophanenin vasfina kılam hikayet

Gör nece kurulmuş yolu erkanı

Birbirine cümle eyler itaat

Gözedirler daim emri fermanı

Aramliyüb gezdim cümle ocağını

Onda gördüm yiğitlerin kucağını

Serhatlara atlı konar otağını

Düşmanın olmağa çok imtihanı

Dolaşır zabitler kir kispetin

Ara etmek içün cümle hizmetin

Dar günde çekerler ocak gayretin

Din yoluna fida ederler canı

Odur Tophanenin bir ser ferazı

Padişah uğruna olmuştur gazi

Avgatı hamsede eder niyazı

Cihanda bulunmaz eşi akranı

Devletin uğruna verdiği candır

Emrine müntezir hazır elandur

Dostuna dost düşmanına düşmandır

Devleti ziyşanın bir gaçar yamanı

Arabacı başı başlarının tacı

Dilerem Mevladan görmesin acı

Sence fukaralar ona duacı

Umarım ki Haktan bula ihsanı

Ol Topçubaşıdır ocağının başı

Zabitlik hakkında bulunmaz eşi 
Ana gelin kimin uğrışa başı

Adalet bostunda süren devranı

Çelebi Efendi cümleye nazır

Ana himmet ede Hazreti Hızır

Kahya Bey devletin emrine hazır

Hizmetinde yokdur zerre nuksanı

Birinci ustası gazi midir kula

Dizilir neferler sağ ilen sola

Yaramaz olanı getirir yola

İder terbiyesi yene isyanı

Arabacı kışlası hoşça binası

Birbirinden ala her bir odas1

Hoş. an1 yaban ustas 1

Seyreder o günde deryacı ğummanı

Beyoğlu kışlası bir hoşça zemin Gezdim her odasin gayet de metin Hak k1lsın cümlesin kederden emin Kör etsün onlara hayin bakana

Cümle arabaya verir metanet Dini Mübin uğruna çekmede gayret Hak Teala vere ona selamet $\mathrm{O}$ da padişahın birkaç aslanı

Her ortada vardır bir odabaşı Vekili harciler verir etmeği aşı

Közedirler anda olan yoldaşı

Daim kaynar kışlalarnın kazanı

Cümle toplar mevcut anda döğülür Gören düşmanlarnın beli bükülür Her serhadının tobı andan çekülür Ahmedi remcidir biri sultanı

Haftada iki gün talim olunur Cümle yoldaşlar mevcut anda bulunur Marifet erbabı olan bilinür Alır bahşışın her kim vursa da nişanı

Talimine çokdur şol idmanları

Devleti andadır aç aslanları Yedi kral içre varur şanları İçlerinde çokdur tabur bozanı 
Neferler talime çıkar dizilir

Gören düşmanlarnın bağrı ezilir

Sitkilen çalışan usta yazılır

Bayasın artırır alur meydanı

Taallüm günü sorar cümlesi baş1

Görenlernin artar kalına coşı

Atlı topçuları iderler koş1

Tabur bağlar cevelan eder devranı

Top ustaları giyer kırmızı fistan

Dahi kalğaları (veliaht) yatsı elan

Süvariler uzun fesiynen beyan

Anların da başka tertip divanı

Komandarı malik bir hub sedaya

Düzer yoldaşları bir hoş sahraya

Gösterir hünerin bay ü gedaya

Alur fendinin her kim varsa izanı

Acep halım kime eyleyim şekval Yandım tahta kehlesinin elinden

Yeter bu her gece çektiğim bela

Yandım tahta kehlesinin elinden

Gayet kumandarı yagşıya can

Kumandarlık ancak yakışır ana

Yayılmış şöhreti anın her yana

Meydanı her yerde kılar cevlanı

Ferman olur bayrakları açılır Mert olan yiğitler onda seçilir Ustalarına ol dem rahmet saçılır Zikir yürerler dilde olur sübhanı

Duasını eyliyüp kalkarlar heman Kimiye etmezler zerrece resyan Doğruca gider nerdeyse mekan

Bir zaman beklerler an da düşmanı

Celali vasfinı eyledim temam

Gezdiği yerde fethin eyler her müdam

Arabacılara eyliyüp makam

Yirmi üç bulur ki tutdı mekan

Her bir köşelerde yüz kişisi var

Hem dahi erkek hem dişisi var 
Karakolda gezer binbaşısı var Yandim tahta kehlesinin elinden

Gündüz olur köşelerde bakarlar Akşam olur tabur tabur çıkarlar Gezdiği yeri akrep gibi sokarlar Yandım tahta kehlesinin elinden

Ezel bıçağımdan yukarı çıkar Değdiği yerleri od gibi yakar Ezilince katı leş gibi kokar Yandım tahta kehlesinin elinden

Oturduğum yerde belim bükülür Tavandan aşağı bir bir sökülür Arka üste yatsam ağzıma dökülür Yandım tahta kehlesinin elinden

Cümlesi de çıkar yerden yollanır Heybetinden canım titrer sallanır Sekizbin tepsi mızrak kullanır Yandım tahta kehlesinin elinden

Irakta olana nağme yazarlar Tabur tabur olur asker düzerler Merdivansız divarlarda gezerler Yandım tahta kehlesinin elinden

Uyku gelir hemin gözüm süzülür Bacamdan yukarı çıkar dizilir Yaptırsam elimden ol dem ezilir Yandım tahta kehlesinin elinden

Uyku gelir gelir gözlerimiz bayılur Karınca gibi gövdemize yayılur Kaşınmaktan derilerim soyulur Yandim tahta kehlesinin elinden

Avumı satayım desem satamam Ayazda yatayım desem yatamam Varıp yaban yerde mekan tutamam Yandım tahta kehlesinin elinden

Döşeğimi basup yastuğum citer İrisi arkağı kum gibi kaynar Atluları çıkar çok cilbiren oynar Yandım tahta kehlesinin elinden 
Bu garip Celali bakar düşünür Subhe dek ber karar durmaz kaşınır

Kaşınmaktan tırnakları aşınır

Yandım tahta kehlesinin elinden

Gel aşığa seni evlendirelim dedim acep güzel midir dedi görünce gameti ar ar hublara sürer kokısı

aynı gayet ilen dilberlileri ahmer gül midir yüzi

şirindir sözi,

aladır gözi,

ya körpe kuz1,

bir doğan aydır,

kaşları yaydır,

bir melek saydır,

hem katı kamet

sahibi mürüvvet

gözleri afet

başında devlet,

vardir letafet,

mahbubi zevan,

bir Mihriban,

kokıs1 reyhan,

bir bir karış gerdan,

dertlere derman,

lebleri mercan,

bir servi revan

bir ince meyan,

gatti baladır,

çeşmi aladır,

derde devadir,

bülbül nevadır,

öpsen vefadır,

guçsan sefadır,

akranı yoktur,

kirpiği oktur,

sanki yamukdur,

kalbe ferahtır,

tubadir ahdir,

hublara sahtır,

kaşı siyahtır,

dişi dürdane

olmaz behane,

gelmez cihane,

nazı reveşi,

yokdırır eşi,

bir gören kişi,

ah olur işi,

yüzünden nuru, 
sanki bir huri, gönlüm sururi, aldır yanağı, kiraz dodağı, bayaz ayağı, dolma gabağı, eşidip bende oldum efkende, ateşe söze düştüm yandım tutuştum, yene inandim, gerçek sandım, söze aldandım, renge boyandim, acele getdiler, tikellehe ettiler, içeri ittiler, gördüm ki bir duvak açtım baktım bir kabak, gördüm ki bir çare asla yok, zarı zarı meradır kiri, bir mezar kurdı gözleri kurşun tavası, kulakları kuşlar yuvası, bir hakkın belası, bir dahı doğurmasın anası, bir kazma dişli, ağzı kesseli bir orak kaşlı, yalın ayakl1, nasir topuklu, bacağı boklu, burnu sümüklü, gözi çapakl1, kalbur kulakl1, cabatır tagl, bir abus yüzlü, hem eğri sözlü, bir çukur gözlü, bir köp karınlı, bir patlican burunlu, hem eyri sözlü, bir çukur gözlü, bir köp karınlı, patlican burunlu hem eğri sözlü, bir çukur gözlü, 


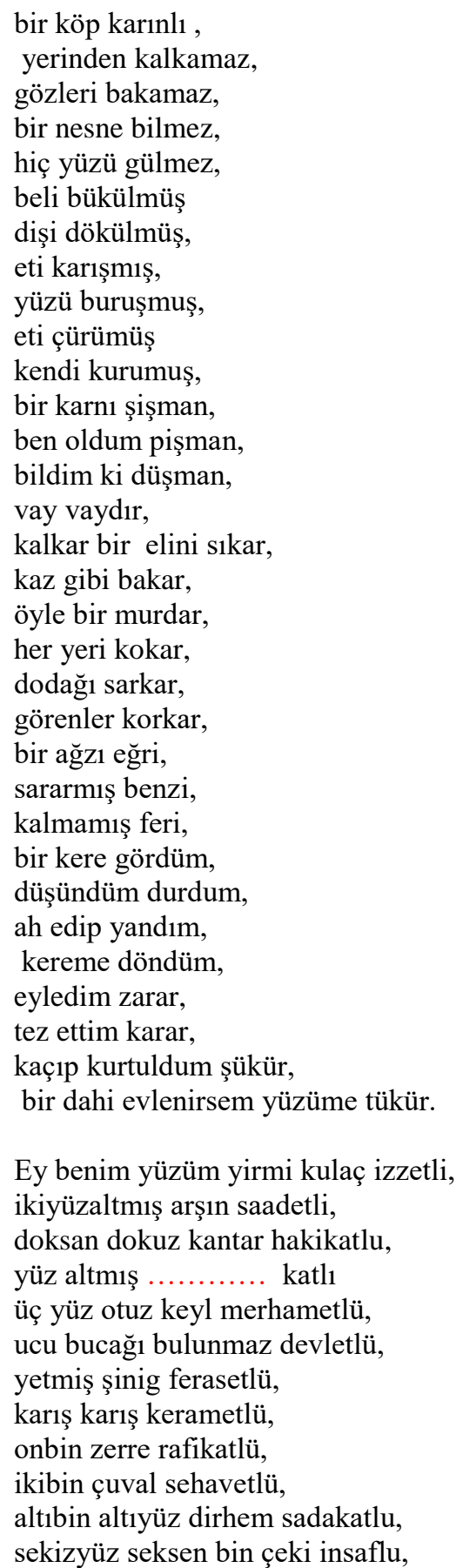

oğulların yüzüme biraderim recebimiz hazretlerine bin üç yüz üç dönüm zevki sefalarda olup kız degin ağzı sini gibi sürmeli ve kızlası gibi büyük dualar olunup, demet demet 
iyilikler, deste deste hoşluklar, torba torba sağlıklarla daim zevki sefada olup tahta kehlesine müşerref olasin amin...

Elif: Allahı seversen gel bize naz eyleme

Be: bize tenezzül edip yanıma gelsen nolur

Te: temam oldum cefalarla düşmanım şad eyleme,

Se: sevaptır aşığına bir ilaç kılsan nolur,

Cim: cemalin aya benzer kaşların ebru(ayru)hilal

Ha: hüsnün ile yaratmış evvel kuddüsi Zülcelal

H1: hudanın emriyle leblerin abi zülal

Dal: deli oldum efendim kadrimi bilsen nolur

Zel: zelillik çekmişem bir aşkına düşeli yene

Re: rahatlık görmemişim vücudum tendedir can

Ze: zibayem mahrum etme hub edersen beni sen

Sin: selamım ya biri bir yün lütfile alsan nolur

Şın: şifasız derde düştüm ya ne cehtim bilemem

Sad: sanardım ağlamaktan gece gündüz gülemem

Dad: zayıf oldum efendim kendi kendim bulamam

$\mathrm{Z1}:$ dilber hatırım sorsan nolur

Ayn: lündür kafir rakip gösterir berri fakan

Gayn: Ğafur Haktan olsun anlara herdem zeval

Fe: fani dünyada bana yadigar olsan nolur

Kaf: kıyamete kalmasın hasretim el aman

Kef: kifayet ider idi yüzünü görsen heman

Lam: lamile lütfüne ersem şad olurdum bir zaman

Mim: meded kıl nazlı yarim yanıma gelsen nolur

Nun: nazarın yok cihanda var eyle yarim benim

He: kemen senin içündür ah ile zarım benim

Lamelif: lamelifle ismü halildür sevgili yarim benim

Ye: yatbı donlu meleğim kadrimi bilsen nolur

KOŞMA::.:.:.:.:.

Nasıl vasfedeyim seni sultanım

Rum ili Bosnaya değer gözlerin

Akranın bulunmaz ruhi revanın

İzmir-ü Kunyaya değer gözlerin

Bu ruyına düzilmiş Yusuf-1 sani?

Gören agtarlar kılar figanı 
Bütün Gürcistanı Erzurum Van'1

Akıskaya değer gözlerin

Kimsede görmedim sendeki nazı

Tunus'u Trablus Misır Hicaz'1

Bağdad Yemen'i Acem Şiraz'1

Balhı Buhara'ya değer gözlerin

Gafuru bendeyem eylerim methin

Yanaktan bir buse olsa himmetin

Yüzbin sarraf olsa bilinmez kıymetin

Büsbütün dünyaya değer gözlerin

Diler bir kalbi macnunu dili şad ettiğin var mı

Muhabbet eyleyüp candan dönüp yar ettiğin var mı

Senin aşkunla ey mihrü harab oldum ezellerden

beni tamu durağından azad ettiğin var mı

düşüp hengameyi aşkın beni mecnun eden sensin teselli eyleyüp kalbimi ayar ettiğin var mı

değül ey Seyfi dahi figan eden bu alemde

bu hale nazar edüp bir imdat ettiğün var mı

İslam padişahı çıktı gazaya

Evliyalar etti ikrar önünce

Sadrazam çekti gayret kılıncın

Bir sücaat etti envarı nunca

Erenler bile dirirdi görenler

Bunca evliyaler bunca erenler

Ricali alemden haber verenler

Yürüdü ahmedi Muhatar önünce

Evliyalar enbiya çağırır hak dost

Aleme temellug dolu vurdi hile (sile) köst

Başucunda altun üskük sürür hile köste

Kırkbin Yeniçeri serdar önünce

Piyade olnuştur nice solaklar

Yalvaralım kimin hakkı dilekler

Yerde evliyalar gökte melekler

Kanat urur çarhı darar(?) önünce 
Saymaz çırağı şem'i yanmada

Fırka bir derviş dahi semavatımda

Seri koltuğumda bade sunmada

Şems-i tebrizi munla nöker önünce

Altıbin yüz aram elleri

Ellibini de fersengin yerleri

Hacı Bektaş ser neferleri

Yürüddü bir hibatın divar önünce

Kahramanı gital şam terin man

Kibleden şumaldan bunca gelen can

Serveri enbiyanın emrine ferman

Şehidler gaziler dört yar önünce

Molla Meşayih ilim kanıdı

Zelfi baltacı iç oğlanları

Huda eksik eylemesin onları

Her biri mensup o dar önünce

Çarhçı yazarlar yigidin hasını

Bari kabul ide bari olmasını

Topçular ceminde top arabasın

Bunca yol açıcı berdar önünce

Her gazaya ferman etti zillah Cümle hazır oldu fi seyrullah

Alemler çıkartır numinallah

Resul sancağı hünkar önünce

Erenler bu ise dediler beli

Kılınç kabzesine vurdular eli

Hüdanın aslanı hazret

Yüridi haydar-1 Kerrar önünce

Yiğitlerim vardır ya misali

Her biri bu dehrin Rüstem-ü zalı

Tatar han sayar mı yedi kralı

Seyyidü kadı ol yar önünce

Mensup mesaciler beyler aşalar

Atbaşı beraber bile aşalar

Derya gibi dalgalanup coşalar

Seri zırıh kulahlı kurar önünce

Erenler bütünü kıblaya döndi

Saf dutup cümlesi secdeye indi

Karacaahmet sultan aslana bindi

Yılandan gamçısı o bimar önünce 
Aradılar bunca iran niranı

Çağırdılar Abdulkadir Geylanı

Mısır gılmanının şahı sultanı

Seyyid Ahmed gibi erva önünce

Şükürler idüp hudap idelüm sena

Senden medet senden kerem Rabbena hafiz inna fetehna

.....canı dilden okur her bar dilince

Kırk bin ... kan keslü rahler sögümde

Gaziler bağı geyüp kanlar düğümde

Cebeciler cebehanesini sağda

Kuşandı silahını tekrar önünce

$\mathrm{Bu}$ gazinin methini diyen erenler

Alimler ilmile döksün rakamlar

Yürüsün haşimi altun alemler

Açılsın sancağı tuğlar önünce

$\mathrm{Bu}$ ahıdır şu yerlerin harabı

Yaslanuk bir zaman taş turabı

Şehitlere sunar Kevser şarab1

Yürüdür sakiler ablar önünce

\section{KAYNAKÇA}

AÇA Mustafa (Ed: M. Öcal OĞUZ), Türk Halk Edebiyatı El Kitabı, Grafiker Yayınları, Ankara:2008

ARTUN Erman, Ansiklopedik, Halkbilimi/Halk Edebiyatı Sözlüğü TerimlerMotifler-Kavramlar, Karahan Kitabevi, Adana:2014

DUYMAZ Ali, Sözün Yazılaşması Yazının Sözleşmesi:Cönkler, Milli Folklor, Y1128, Say1:111, 2016

GÖKYAY Orhan Şaik, Türk Diyanet Vakfi İslam Ansiklopedisi Cilt:8, Türkiye Diyanet Vakfı Yayın Matbaacılık ve Ticaret İşletmesi, Ankara: 1993

GÜZEL Abdurrahman, TORUN Ali, Türk Halk Edebiyatı El Kitabı, Akçağ Yayınları, Ankara:2008

KAYA Doğan, Ansiklopedik Türk Halk Edebiyatı Terimleri Sözlüğü, Akçağ Yayınları, Ankara:2010 